\title{
Studies of standard heterosis for quantitative traitsin eggplant (Solanum melongena L.)
}

\author{
VENKATA NARESH BODDEPALLI*, A.K. DUBEY AND M.R. DABBAS \\ Department of Vegetable Science, C.S. Azad University of Agriculture and Technology, KANPUR (U.P.) INDIA
}

\begin{abstract}
Standard heterosis has been amply exploited in developing hybrids in eggplant by increasing commercial value of them. In an experiment, fifteen parents (12 lines and 3 testers) were selected on the basis of divergence and mated them in line $\mathrm{x}$ tester design. Hybrids and parents rose to measured heterosis for different quantitative traits. Some of the hybrids exhibited positive standard heterosis. In case of days to 50 per cent flowering, plant height and days to maturity, where negative heterosis is desirable, seven hybrids showed negative standard heterosis for days to 50 per cent flowering, twenty four hybrids for plant height and three hybrids showed significant negative heterosis for days to maturity. For number of branches per plant, three hybrids showed significant and twenty hybrids showed positive standard heterosis. In case of fruit length and fruit diameter both positive and negative heterosis was observed. Twenty six hybrids showed positive standard heterosis for number of fruits per plant. Yield, the ultimate product of different yield components, nine hybrids showed positive standard heterosis for yield. In case of Cercospora leaf spot incidence, seventeen hybrids showed highly significant standard heterosis.
\end{abstract}

Key Words : Eggplant, Standard heterosis, Quantitative traits, Cercospora leaf spot

View Point Article : Boddepalli, Venkata Naresh, Dubey, A.K. and Dabbas, M.R. (2016). Studies of standard heterosis for quantitative traitsin eggplant (Solanum melongena L.). Internat. J. agric. Sci., 12 (1) : 38-41.

Article History : Received : 14.07.2015; Revised : 16.11.2015; Accepted : 30.11 .2015

\footnotetext{
* Author for correspondence :
} 